\title{
The Relationship Between Awareness of and Respect for the Rights of the Patients With Mental Disorders From the Perspective of Nurses
}

\author{
Razie Jooj ${ }^{1}$; Fatemeh Hajibabaee ${ }^{2, *}$; Kourosh Zare ${ }^{1}$; Mohammad Hossein Haghighizade ${ }^{3}$ \\ ${ }^{1}$ Department of Nursing, School of Nursing and Midwifery, Ahvaz Jundishapur University of Medical Sciences, Ahvaz, IR Iran \\ 2 Department of Nursing Management, School of Nursing and Midwifery, Tehran University of Medical Sciences, Tehran, IR Iran \\ 3 Department of Biostatistics, School of Health, Ahvaz Jundishapur University of Medical Sciences, Ahvaz, IR Iran \\ ${ }^{*}$ Corresponding author: Fatemeh Hajibabaee, Department of Nursing Management, School of Nursing and Midwifery, Tehran University of Medical Sciences, Tehran, IR Iran. Tel: \\ +98-9188141451, Fax: +98-8138378388, E-mail: hajibabaeefateme@yahoo.com
}

\begin{abstract}
Background: Because of the nature of their disease, patients with mental disorder are more at risk and usually fail to recognize their natural rights in comparison to other patients.

Objectives: The present study aims to determine the relationship between nurses' awareness of the rights of patients with mental disorder and the respect for the rights from nurses' perspective.

Patients and Methods:This research is a cross-sectional study whose participants were 43 nurses working in psychiatric wards of hospitals in Ahvaz. We used questionnaires to collect data that was analyzed using descriptive statistics and Pearson correlation coefficient test. Results: Awareness of the majority of nurses about the rights of the patients with mental disorder and respect for their rights from their perspective were at a good level. Using Pearson correlation coefficient test, a statistically significant correlation was found between the level of awareness of and the respect for their rights from the perspective of nurses $(P \leq 0.002)$.

Conclusions: This study clearly showed a significant correlation between awareness of and respect for the rights of patients with mental disorder from the nurses' perspective. Also, considering the specific condition of these patients and psychiatric wards, relevant authorities should take further measures to increase awareness of the healthcare staff regarding the rights of these and subsequently increase its compliance so that we witness the practical and real respect for patients' rights by medical staff.
\end{abstract}

Keywords:Patient Rights; Nurses; Awareness; Iran

\section{Background}

The patient's rights are among the main indicators in defining standards of medical services. The principle of respect for patient's bill of rights in any society is one of the most important concepts in medical ethics, with a long history. Patient's bill of rights aims to protect the patients' rights and ensures their adequate care. It can improve the relationship between patients and healthcare staff and enhances the quality of health and medical care (1). The patients' bill of rights defends human rights to preserve their sanctity and dignity, to ensure that in the event of illness, especially in emergency situations, enough care will be taken to their lives and well-being, regardless of age, sex and financial status, provided in a quality environment of full respect.

Human being as a physical, mental, social and spiritual creature, has the rights during health and disease, which cannot be defended, acquired and protected, without others' help. Therefore, the emphasis on basic human rights during health and medical care, especially on dignity of the patient as a human being, is more important when the vulnerability of patient makes him or her easily susceptible to violations and weaknesses of the health system (2).
One of the issues addressed in the discussion of the patient's rights in recent years has been the respect for the rights of inpatients in medical centers and psychiatric wards and the need for improved legislation to protect the patients with severe mental disorder. As people with mental disorders are the most vulnerable group of the society, it is necessary to defend their rights, which are being violated in various ways. In many cases, patients with mental disorders have been denied their right to live freely, with no supervision and no legal right. This means that many of them are forced to stay for several years in the mental health institutions and centers, despite their ability to make decisions about their lives and future.

For various reasons such as low health and medical credits as well as hospital bed shortages, they are denied from the right of the access to essential health care services. Their satisfaction with the treatment process and services offered at these centers are usually being ignored. During hospitalization, autonomy and freedom of individuals (such as a free relationship and appointments to their relatives) is ignored due to insufficient constraints (3). Since mental illnesses have various features and human 
Jooj Ret al.

insight is constantly changing, it is difficult to formulate universal laws that can involve rights of all patients with mental disorder. However, awareness of nurses and other medical staff, about relevant codified rules has a crucial role in advancing the treatment, as well as human and legal goals (4). Nurses are the largest group of professionals (about $40 \%$ of staff) and have a clear role in providing medical care in the healthcare system(5). Besides, the role and responsibility of nurses change day by day and gain a wider scope.

Legal standards imply that nursing has been recognized as an independent and special career in legal and medical communities. This role requires nurses to have high awareness and skills as well as the ability to make decisions.

Therefore, lack of awareness in the nursing profession is a crime in itself, rather than a barrier to evade the law. Hence, to protect the rights of the patients and healthcare providers, the provisions of the law must be taught to both groups. Meanwhile, nurses must strive for constant improvement of high standards in patient care, protection of their safety and health, acquiring legal information related to their profession, to provide effective care (6).

A descriptive analytical study conducted by Hooshmand et al. in 2006 on 554 nurses working in the public sector of educational hospitals in Tehran, holding a work experience of least six months, showed that although the nurses had a high awareness of the concept of patient's rights, respect for the rights, from their perspective, they need the requirements that are not currently available and produce some problems for this important moral issue. Therefore, it seems that the attention of the authorities is of special importance to ensure the rights of the patients (7). Likewise, Suvapap's study on the respect for the rights of the patients from the view of nurses (as important members of any healthcare team), which was conducted on 148 nurses working in Nakorn Ping Hospital, Chiangmai Province, showed that the respect levels were moderate, high and low by $69.5 \%, 16.2 \%$, and $14.1 \%$ of nurses, respectively. Score of nurses was 40.01 points out of a total score of 50 , i.e. $80 \%$. Due to the misunderstanding of patient's rights in many sentences of the questionnaire, training programs for the staff in the health system is considered necessary to respect the rights of patients (8).

One of the few studies regarding the rights of patients with mental disorder in Iran is the study conducted by Abbasi et al. entitled "The medical staff and hospitalized patients' attitude in selected psychiatric hospitals in Tehran about adaptation of patients' rights charter of patients with mental disorder in 2010". They concluded that the patient's bill of rights in Iran cannot fully meet the needs of these patients (3). Furthermore, the results of the another study, entitled 'Study of psychiatrists' knowledge, attitude, and practice toward compulsory admission of psychiatric patients and its related laws in Iran in 2006," which was conducted by Valipour et al. showed that the consequences of lack of awareness are seen in the performance of the majority of psychiatrists. These findings suggest the numerous limitations in existing laws and lack of trained psychiatrists in the country, which require urgent measures for better legislation and more inclusive training of psychiatrists (4). In our country, no study has been so far performed on the awareness of the rights of inpatients with mental disorders and respect for them. Compared to other members of the care-providing team, nurses are in continuous contact with the patients, which highlights the importance of this issue.

\section{Objectives}

This study was performed to determine the relationship between nurses' awareness of the rights of patients with mental disorder and respect for the rights from their perspective in therapeutic educational centers affiliated to Ahvaz University of Medical Sciences.

\section{Patients and Methods}

This study is a cross-sectional one, which examined the relationship between nurses' awareness of the rights of patients with mental disorder and respect for their rights from nurses' perspective. The population of this study included all nurses working in Salamat Psychiatric Hospital and psychiatric wards of Sina and Golestan hospitals in Ahvaz in 2012. All the nurses working in psychiatric wards who met the criteria were enrolled. Inclusion criteria were at least one year of working in psychiatric wards, and holding associate degree or higher. Questionnaires were given to 43 nurses by the researcher, with the cooperation of supervisors and head nurses. Finally, after repeated follow-ups, 43 nurses personally returned their completed questionnaires to the researcher.

This study was approved by the Ethics Committee of Ahvaz University of Medical Sciences, and before starting work, the researcher obtained the necessary permits from the relevant authorities. To enter the study, the researcher referred to the psychiatric wards in the morning, afternoon and evening shifts. The researcher gave the participants sufficient information about the study objectives, its importance, anonymity, and voluntary participation as well as confidentiality of their information. After obtaining informed consent, the questionnaire was provided to the nurses who received necessary information about how to complete it. The nurses completed the questionnaires through self-reporting and a week later, submitted them to the researcher.

Considering the purpose of the study, a researcher-designed instrument was used, using three sources: 1) Patient's bill of rights approved by the Ministry of Health and Medical Education. 2) Issues raised in the patient's bill of rights, drawn from the review by Parsapour, and 3) The legal fundamentals of mental health care on inpatients, prepared by the World Health Organization (WHO). In the study by Abbasi et al. this tool was designed to exam- 
ine the nurses' attitude toward the questionnaire.

The questionnaire consisted of three parts. The first part included demographic information, such as age, sex, marital status, position, education level, work experience in the psychiatric ward, and employment status. The second part of the questionnaire was related to the nurses' awareness and consisted of 28 items. Each statement was evaluated with two options: "I know" and "I don't know"; and each question was rated a minimum of zero and a maximum of one. On the whole, the total scores were at least zero and at most 28, respectively. The scores from 0 to 9 were considered poor awareness; from 10 to 18 average awareness, and from 19 to 28 good awareness.

Third part, with 28 items was related to the level of respect for the rights, and each statement was scored by the Likert method, from 1 (very low) to 5 (very high). In general, total scores were at least 28 and at most 140 . The score 28 or lower for very low, 29 to 56 for low, 57 to 84 for moderate, 85 to 112 for good, and 113 to 140 for excellent level of respect for the rights. Content validity was used to determine the scientific validity of the instrument. The designed tool was given to ten members of Ahwaz's faculty of nursing and midwifery, who had expertise in nursing research and ethics, and necessary modifications were made after collection of their expert opinions.

To confirm the reliability of the instruments, we used Cronbach $\alpha$ coefficient, whose value was equal to 0.86 and 0.95 for the questionnaire concerning the awareness and the level of respect for the rights, respectively. Data analysis was performed using descriptive statistics and Pearson correlation coefficient statistical test. In addition, we applied SPSS software version 21.

\section{Results}

According to the study, $55.8 \%$ of the nurses were between 31-40 years old among which more than half (60.5\%) were men. Approximately, 35 participants (81.4\%) were married, and 30 participants (69.8\%) were formally employed (Table 1). The nurses were from the psychiatric wards of Golestan Hospital (32.6\%), Sina Hospital (27.9\%), and Salamat Hospital (5/39\%). The majority of nurses in the study (79.1\%) had good awareness of the rights of patients with mental disorder (Table 2). The mean and standard deviation of awareness were $22.06 \pm 4.89$, respectively, which were at a good level. In addition, the perspective of more than half of the nurses (51.2\%) about respect for the rights of patients with mental disorder were at a good level, with a mean and SD of 109.55 \pm 19.57 (Table 3). Using Pearson correlation coefficient test, a direct and significant correlation was found between the awareness levels of the samples and the levels of respect for the rights of patients from their perspective ( $\mathrm{P} \leq$ 0.002). Regarding the relationship between demographic variables and awareness level of nurses, no significant relationship was found between the awareness level and demographic information.
Table1. Frequency of Demographic Information About the Studied Nurses

\begin{tabular}{|lc}
\hline Demographic Information & Frequency, No. (\%) \\
\hline Sex & \\
\hline Male & $26(60.5)$ \\
\hline Female & $17(39.5)$ \\
\hline Total & $43(100)$ \\
\hline Marital status & \\
\hline Single & $8(18.6)$ \\
\hline Married & $35(81.4)$ \\
\hline Total & $43(100)$ \\
\hline Age, $\mathbf{y}$ & \\
\hline $21-30$ & $15(34.9)$ \\
\hline $31-40$ & $24(55.8)$ \\
\hline $41-50$ & $4(9.3)$ \\
\hline Total & $43(100)$ \\
\hline
\end{tabular}

Education level

Associate degree

$22(51.2)$

BS degree $20(46.5)$

Master's degree

$1(2.13)$

Total $43(100)$

\section{Employment status}

\begin{tabular}{lc} 
Project-based & $4(9.3)$ \\
Contractual & $9(20.9)$ \\
\hline Official (contract) & $30(69.8)$ \\
Total & $43(100)$
\end{tabular}

Work experience, $y$

$\begin{array}{ll}1-5 & 13(30.2) \\ 6-10 & 11(25.6) \\ 11-15 & 12(27.9) \\ \text { Total } & 43(100)\end{array}$

Work experience in the psychiatric ward, $y$

\begin{tabular}{lc}
$1-5$ & $20(46.5)$ \\
$6-10$ & $9(20.9)$ \\
$11-15$ & $12(27.9)$ \\
$>15$ & $2(4.7)$ \\
Total & $43(100)$ \\
Position & \\
Head nurse & $2(4.7)$ \\
Nurse & $41(95.3)$ \\
Total & $43(100)$ \\
\hline
\end{tabular}


Table 2. Frequency Distribution and Percentage of Awareness of Samples of the Rights of Patients with Mental Disorder ${ }^{\text {a }}$

\begin{tabular}{lc}
\hline Frequency & Awareness Level, No. (\%) \\
\hline Weak & $1(2.3)$ \\
Average & $8(18.6)$ \\
Good & $34(79.1)$ \\
Total & $43(100)$ \\
\hline${ }^{\mathrm{a}}$ Mean $\pm S \mathrm{SD}=22.06 \pm 4.89$. &
\end{tabular}

Table 3. Frequency Distribution and Percentage of Respect for the Rights of Patients With Mental Disorder in Samples ${ }^{\text {a }}$

\begin{tabular}{lc}
\hline Frequency & Respect for the Rights of Patient, No.(\%) \\
\hline Very Low & $0(0)$ \\
\hline Low & $0(0)$ \\
Average & $3(7)$ \\
Good & $22(51.2)$ \\
Excellent & $18(41.9)$ \\
Total & $43(100)$ \\
\hline
\end{tabular}

$\mathrm{a}$ Mean $\pm \mathrm{SD}=109.55 \pm 19.57$

\section{Discussion}

The study results showed that there was a significant relationship between the awareness level of the participants and the level of respect for the rights of patients with mental disorders from their perspective. Pearson correlation coefficient test showed that level of respect for the rights of patients with mental disorders also increased by increasing its awareness level $(P \leq 0.002)$. In a study by Nasiriany et al. there was a significant relationship between awareness of and respect for the rights of the patient by nurses, which was a direct linear relationship and also increased by increasing the awareness of the patients' rights (6). This finding is consistent with the results of the present study. It is certain that awareness of anything is a necessity to do it in a right way. In addition, the first condition to respect the rights of patients is sufficient awareness of their rights. When nurses are unaware of these rights, they cannot be expected to be respected too. However, studies have shown that respect for the rights of patients requires the formation of ethical committees, the provision of information to the patients about their rights, and the introduction of new legislation (7).

Regarding the awareness level, the findings of the present study showed that awareness level of most nurses of the rights of the patients with mental disorder (79.1\%) was at a good level. This finding was consistent with the study conducted by Hooshmand et al. Regarding the awareness level of nurses of patients' rights; they concluded that nurses in the study have high awareness of patient rights in most cases (95.5\%), and in other cases, awareness was at an average level (7). In addition, the results of the study by Nasiriani et al. in 2007, entitled "Study of respecting patient's rights from nurses point of view employed in Yazd hospitals" had suggested that the nurses 'awareness of patients' rights is at a good level (9). In contrast, a study by Ghaljeh et al. found that nurses' awareness of patients' rights was at an average level (10). It is certain that if nurses working in psychiatric wards have no awareness of ethical concepts and related issues, including patient rights, they could neither face the challenges ahead nor comply with needs of the unique conditions of these patients. Therefore, this concept is of special importance for providing quality care.

In the present study, the level of respect for the rights of patients from the perspective of nurses was at a good level in more than half of the nurses (51.2\%). In their study, Nasiriani et al. concluded that respect for the rights of patients by nurses is at moderate level and is not satisfactory (9). It should be noted that respect for the rights of patients has several dimensions and is influenced by many factors that cannot be reviewed in a cross-sectional study. Therefore, this can be considered as one of the limitations of this study.

The findings of the present study revealed that the greatest level of awareness is associated with the items of "responsiveness of treatment team to questions of the patient or her/his substitute decision maker about illness and care" and "the provision of sufficient information about the disease in a language understandable to the patient or her/his substitute decision maker". Some studies suggest that nurses have stressed the need to provide the patient information about the health facility regulations and about the treatment and its complications $(11,12)$. In addition, the least awareness level is associated with the items of "awareness of their cost and the right to object" and "expression of the error occurred during service delivery to the patients by the person who commits the error."

These results were consistent with the findings reported by Parsapour et al. and Abbasi et al. In their study, nurses believed that there is no definite need to state a medical error to the patients. Perhaps the nurses were concerned that if they stated the errors to patients, they might lose their confidence in the treatment team and refrain from further therapy $(3,11)$. However, it seems that the expression of error is essential due to the responsibility that the conscience of nurse has for the patient's trust. Therefore, further research on the way and conditions of expression of treatment error can be helpful.

The greatest level of respect for the rights in the samples was associated with the items of "provision of diagnostic medical services without discrimination" and "provision of diagnostic medical services to patients at the earliest possible time". In addition, the least level of respect for the rights was related to the items of "patient access to his or her medical records and awareness of its content" and "awareness of medical skill, tariff rates and insurance coverage". The results of the study are in agreement with 
the study by Parsapour, whose findings showed special sensitivity and importance of these rights for the studied groups (11). In addition, the study by Bostani Khalesi showed that all the studied groups agreed on respectfully receiving services, without discrimination, by patients (1). On the other hand, the findings of this study are well consistent with the results of Parsapour's study, which showed that the patient's access to his or her medical records or the awareness of its content was not regarded as a necessity by physicians and nurses (11).

Regarding the patient's attitude toward respect for the rights of patients in educational hospitals affiliated to Isfahan University of Medical Sciences, Keshvari et al. also reported that only $43.3 \%$ of patients were justified for tariff rates and health care coverage (13). The patient's right is effectively realized when they have complete information for a wise decision. According to Burke, the medical expediency should not deny the right to autonomy of a patient by hiding relevant information. He believes that individual's ownership of his or her body is the basis of the right to receive relevant information. This right, as an ethical standard, is a reason to object to lying, cheating and hiding information, which has been approved by patient's bill of rights in Iran ratified in 2010. In other words, the patient has the right to receive accurate and understandable information about health plans and health care facilities. Even if the patient speaks a different language or has a physical or mental disability, he or she must be helped in some way to receive the necessary information to make decisions (14).

As this study clearly showed a significant relationship exists between awareness of and respect for the rights of patients with mental disorder from the perspective of nurses. Thus, considering the sensitivity and condition of the patients with mental disorder and psychiatric wards, relevant authorities should take measures to increase the awareness of healthcare workers of the rights of these patients, and subsequently increase its compliance so that we can see the practical and real respect for the patients' rights by medical staff.

\section{Authors' Contributions}

Razie Jooj was involved in the study conception, design and analysis/interpretation of data. Fatemeh Hajibabaee was involved in the study conception, design, analysis/ interpretation of data, drafting of the manuscript, critical revisions for important intellectual content and re- view of content. Kourosh Zare was involved in the study conception, design, material support and critical revisions for important intellectual content. Mohammad Hossein Haghighizade was involved in the study design, provision of statistical technical support and review of the content.

\section{Funding/Support}

This study was funded by the vice chancellor for research and technology, Ahvaz Jundishapur University of Medical Sciences.

\section{References}

1. BostaniKhalesi Z, Masole S, Abedinzade M. [Evaluation of the Patients, Doctors and Nurses View Points about Patient Bill of Rights in Rasht Public Hospitals]. J Fasa Univ Med Sci. 2012;2(2):91-5.

2. Jouziarkovazi H, Ashktora,T،, basi M, Delpishe A. [Perspectives of nurses and patients in the patient's rights]. IJME. 2010;89(17):5.

3. Abbasi M, Rshidian A, Arab M, Mini H, Hoseini M. [Medical Staff and Hospitalized Patients Attitude in Selected Psychiatric Hospitals in Tehran about Adaptation of patients Rights Charter of patients with Mental Disorder]. Iran J Psych Clin Psychol. 2010;16(3).

4. Valipour M, Zarghami M, Masoudzadeh A, Khalilian A, Tirgari A, Mosavi S. [Study of Psychiatrists' knowledge, attitude, and practice toward compulsory admission of psychiatric patients and its related laws in Iran in 2006]. J Mazandaran Univ Med Sci. 2007;17(61):148-60.

5. Sullivan E. Effective Management in Nursing.California: Addison Wesley publishing; 1996.

6. Nasiriany KH, Salemi S, Salman Yazdy N, Hosseini F. [How Nurses Respect Patient's Rights]. IJN. 2002;15(32 and 33):8-14.

7. Hooshmand A, Joolaee S, Mehrdad N, Bahrani N. [Nurses' information and their view points about patient's rights and practical facilitators in clinics]. Hayat. 2006;12(4):57-66.

8. Suvapap T. Perception of patients rights among nurses in Nakorn Ping hospital chiangmai province.. Available from: http://www.yahoo.com.2002.

9. Nasiriani K, Farnia F, Nasiriani F. [Study of respecting patients rights from nurses point of view employed in Yazd hospitals]. Sci J Forensic Med. 2007;13(1):33-7.

10. Ghaljeh M, Zakeri Z, Rezaee N, Abedzadeh R. [physicians and nurses awareness and function about patients right charter in zahedan]. Int J Med Educate. 2010;3(2):69-75.

11. Parsapour, A. , Mohammad K, MalekAfzali K, Larijani B. [The necessity of observing patients' right: surveying patients', physicians' and nurses' attitudes around it]. IJME. 2009;2(4):79-90.

12. Guix Oliver J, Fernandez Ballart J, Sala Barbany J. [Patients, physicians and nurses: three different points of view on the same issue. Attitudes to and perceptions of patient rights]. Gac Sanit. 2006;20(6):465-72.

13. Keshvari M, Hosseini F, FarajZadegan Z. [Investigation of attitudes ofpatientson the respectpatients' rightscharter in Isfahan hospitals]. First Congress of patients'rightscharter. Fasa University of Medical Sciences. 2001.

14. Alizadeh M. [Nursing ethics during the life].Iran: Boshra publication; 1994 . 